\title{
The Clinical Autonomic Research journal 2018 and onward
}

\author{
Horacio Kaufmann ${ }^{1,3}$. Jens Jordan ${ }^{2}$
}

Received: 22 December 2017 / Accepted: 23 December 2017 / Published online: 2 February 2018

c) Springer-Verlag GmbH Germany, part of Springer Nature 2018

The status of Clinical Autonomic Research is excellent. As of December 2017, we handled over 250 submissions of several types and categories. The average time from submission to initial decision was only 15 days, and to final decision was just 35 days. The average time from acceptance to online publication was 21 days. This is an extremely fast turnaround time for a peer-reviewed scientific journal, making Clinical Autonomic Research a perfect instrument for fast publication of high-impact research manuscripts. Our social media relevance continues to grow thanks to our Facebook (http://www.facebook.com/ClinAutonRes) and Twitter (@ ClinAutonRes) presence, with over 400 social media mentions of articles published in our journal in 2017.

We would like to underline the enormous value and dedication of our Associate Editors who provide work of excellence for the assessment of every submission they manage. We have strengthened our Associate Editors team with the addition of Dr. André M. Diedrich, Professor of Medicine at Vanderbilt University. Also, we are very thankful to Dr. David S. Goldstein and Dr. William P. Cheshire for their outstanding series on Autonomic Function Testing [2, 3], which will continue in 2018 .

Overall, we shall renew our effort to publish the latest advances and topics generating the greatest interest. For instance, this issue of the journal includes a review by Dr. Jean-François Brunet, who recently proposed a world-shattering re-classification of the autonomic pathways [1]. As expected, not everybody agrees with Dr. Brunet, and, also in this issue, we include counterpoint comments by Dr. Wilfrid Jänig and Dr. Frances Lefcort. This issue also includes

Horacio Kaufmann

Horacio.Kaufmann@nyu.med.edu

1 Department of Neurology, New York University School of Medicine, New York, USA

2 Institute of Aerospace Medicine, German Aerospace Center, Cologne, Germany

3 Clinical Autonomic Research Editorial Office, 530 First Avenue, Suite 9Q, New York, NY 10016, USA a state-of-the-art review on the endocannabinoid system in cardiovascular function, underlying the growing interest of the potential medical applications of cannabis [5]. These are just examples of how Clinical Autonomic Research continues to be the benchmark publication in the field of autonomic medicine and a primary forum for communicating new and important scientific information in this area.

On a practical note, we would like to restate that Clinical Autonomic Research continues to welcome submissions of case reports and autonomic images, in the form of Letter to the Editors. We believe these are particularly attractive article formats for students, residents, and fellows, and anyone aiming to report striking images, such as the one included in this issue (you will never eat macaroni the same way again!) [4].

As usual, this issue includes the list of the reviewers during 2017. We are extremely grateful for their outstanding support in maintaining the quality of the journal.

On behalf of the Editorial Team of Clinical Autonomic Research, we would like to wish the American Autonomic Society members, the European Federation of Autonomic Society members, our readers, our authors, and our reviewers a fruitful and very happy 2018.

Horacio Kaufmann MD Jens Jordan MD PhD

Editors-in-Chief

\section{References}

1. Espinosa-Medina I, Saha O, Boismoreau F, Brunet JF (2017) The "sacral parasympathetic": ontogeny and anatomy of a myth. Clin Auton Res. https://doi.org/10.1007/s10286-017-0478-7 (Epub ahead of print)

2. Goldstein DS, Cheshire WP Jr (2017) The autonomic medical history. Clin Auton Res 27:223-233

3. Goldstein DS, Cheshire WP Jr (2017) Beat-to-beat blood pressure and heart rate responses to the Valsalva maneuver. Clin Auton Res 27:361-367

4. Palma JA, Spalink C, Barnes EP, Norcliffe-Kaufmann L, Kaufmann H (2017) Neurogenic dysphagia with undigested macaroni 
and megaesophagus in familial dysautonomia. Clin Auton Res. https://doi.org/10.1007/s10286-017-0487-6 (Epub ahead of print)

5. Sierra S, Luquin N, Navarro-Otano J (2017) The endocannabinoid system in cardiovascular function: novel insights and clinical implications. Clin Auton Res. https://doi.org/10.1007/s1028 6-017-0488-5 (Epub ahead of print) 